\title{
lonosphere-thermosphere (IT) response to solar wind forcing during magnetic storms
}

\author{
Cheryl Yu-Ying Huang ${ }^{1}{ }^{*}$, Yanshi Huang ${ }^{2}$, Yi-Jiun Su${ }^{1}$, Eric K. Sutton ${ }^{1}$, Marc Rotan Hairston ${ }^{3}$, \\ and William Robin Coley ${ }^{3}$ \\ 1 Air Force Research Laboratory, Kirtland AFB, NM 87117, USA \\ ${ }^{*}$ Corresponding author: cheryl.huang@us.af.mil \\ 2 University of New Mexico, Albuquerque, NM 87131, USA \\ 3 University of Texas at Dallas, Richardson, TX 75080, USA
}

Received 6 March 2015 / Accepted 3 July 2015

\begin{abstract}
During magnetic storms, there is a strong response in the ionosphere and thermosphere which occurs at polar latitudes. Energy input in the form of Poynting flux and energetic particle precipitation, and energy output in the form of heated ions and neutrals have been detected at different altitudes and all local times. We have analyzed a number of storms, using satellite data from the Defense Meteorological Satellite Program (DMSP), the Gravity Recovery and Climate Experiment (GRACE), Gravity field and steady-state Ocean Circulation Explorer (GOCE), and Thermosphere Ionosphere Mesosphere Energetics and Dynamics (TIMED) mission. Poynting flux measured by instruments on four DMSP spacecraft during storms which occurred in 2011-2012 was observed in both hemispheres to peak at both auroral and polar latitudes. By contrast, the measured ion temperatures at DMSP and maxima in neutral density at GOCE and GRACE altitudes maximize in the polar region most frequently with little evidence of Joule heating at auroral latitudes at these spacecraft orbital locations.
\end{abstract}

Key words. Ionosphere - Thermosphere - Solar wind - Polar cap - Energy distribution

\section{Introduction}

Over many years of research into the effects of solar wind forcing on the ionosphere-thermosphere (IT) system, it has been generally assumed that energy enters and dissipates in the auroral zones and ring current (Akasofu 1981; Weiss et al. 1992; Knipp et al. 1998; Li et al. 2012, and references therein). This assumption is based on the effect of particle precipitation which gives rise to intense auroral emissions and high conductivity in the auroral zone (Evans et al. 1977; Vondrak \& Robinson 1985; Fuller-Rowell \& Evans 1987; Coumans et al. 2004, and many others). While conductivity is essential to Joule heating of ions, it was not until comparisons of energy input from solar radiation, electromagnetic waves in the form of Poynting flux, and particle precipitation were carried out that the relative contributions to the IT energy budget were realized (Knipp et al. 2004; Huang et al. 2014a). In these and other studies, it was shown that Poynting flux is by far the dominant source of energy into the IT system, with typical ratios of 3 to 10 of Poynting flux to particle precipitation power.

The main point of our previous study of IT coupling during the August 2011 magnetic storm (Huang et al. 2014a) was the magnitude of the energy required to explain Joule heating of the thermosphere. We hypothesized that the Poynting flux extrapolated from the Weimer model (Weimer 2005) (hereafter W05) modified by Defense Meteorological Satellite Program (DMSP) measurements underestimates the power available to the IT system via the polar cap. Poynting flux input to the high-latitude ionosphere has been reported by Knipp et al. (2011), Wilder et al. (2012) and modeled by Crowley et al. (2010) and Li et al (2011). High-latitude storm-related neutral density maxima in the cusp and polar cap have been reported by Lühr et al. (2004) and Liu et al. (2010). However, a systematic investigation of the polar cap as a possible locus of energy dissipation and subsequent IT heating has not been undertaken.

Continuing on from the study by Huang et al. (2014a), we examine details of where Poynting flux is observed in local time, and where ion temperature and neutral density variations occur during three selected storms which occurred on August 5-6, 2011, September 26, 2011, and January, 2012. Our goal is to determine the locations at which high Poynting flux is observed, and to examine the Joule heating response in the observed ion temperatures $\left(T_{\mathrm{i}}\right)$ and neutral densities $(\rho)$. The only source of continuous monitoring of $T_{\mathrm{i}}$ is from the DMSP spacecraft of which four were operational, F15, F16, F17, and F18. We use the measured $T_{\mathrm{i}}$ as a proxy for Joule heating of ions. The effect of Joule heating of neutrals is a change in observed $\rho$ at a fixed altitude. If energy is transferred to neutrals at a specific altitude, the result is an expansion of the thermosphere. At a fixed altitude above the energy dissipation region, the neutral density will increase. In this study we treat observations of increased neutral density as evidence of localized Joule heating occurring below the observation point.

Our sources of neutral density measurements are GOCE (Gravity field and steady-state Ocean Circulation Explorer) at an average altitude of $275 \mathrm{~km}$ and GRACE (Gravity Recovery and Climate Experiment) at an average altitude of $470 \mathrm{~km}$ during 2011-2012. We also refer to the observed $\mathrm{O} / \mathrm{N}_{2}$ ratio detected by the Global Ultraviolet Imager (GUVI) on the Thermosphere Ionosphere Mesosphere Energetics and Dynamics (TIMED) satellite, and the Special Sensor Ultraviolet Spectrographic Imager (SSUSI) on the DMSP satellite. The UV 
images offer a proxy for Joule heating of neutral oxygen at altitudes between 135 and $200 \mathrm{~km}$ (Zhang et al. 2004). The $\mathrm{O} / \mathrm{N}_{2}$ observations, combined with the in situ observations from GOCE and GRACE, enable an altitude profile of heated neutrals during the storms.

Combining the data available related to energy input and dissipation we conclude that the polar cap is a locus of significant energy transfer to ions and neutrals during magnetic storms and should be included in any analysis of the IT response to storm-related driving.

\section{Instrumentation}

Defense Meteorological Satellite Program satellites are threeaxis stabilized spacecraft that fly in circular, Sun-synchronous, polar (inclination $98.7^{\circ}$ ) orbits at an altitude of approximately $840 \mathrm{~km}$. The geographic local times of the orbits are near the 1800-0600 (F16, F17), 1700-0500 (F15), or 2000-0800 (F18) local time meridians. Offsets between the geographic and geomagnetic poles allow DMSP satellites to sample wide ranges of magnetic local times over the course of a day. The ascending nodes of DMSP orbits are on the dusk side of the Earth. Thus, the satellites move toward the northwest in the evening sector and southeast in the morning sector. Each satellite carries sensors to measure densities, temperatures, and drift motions of ionospheric ions and electrons (Special Sensor for Ions, Electrons, and Scintillations [SSIES]). All of the satellites carry magnetometers (Special Sensor for Magnetic Fields [SSM]) to monitor perturbations of the Earth's magnetic field.

Each SSIES instrument package consists of a spherical Langmuir probe mounted on a $25 \mathrm{~cm}$ boom to measure the density and temperature of ambient electrons and three different sensors mounted on a planar conducting plate facing the ram direction. These are (1) an ion trap to measure the total ion density, (2) an ion drift meter (IDM) to measure horizontal $\left(V_{\mathrm{H}}\right)$ and vertical $\left(V_{\mathrm{V}}\right)$ cross-track components of the plasma drift, and (3) a retarding potential analyzer (RPA) to measure ion temperatures and in-track components of plasma drift $V_{\mathrm{k}}$ (Rich \& Hairston 1994). Shapes of RPA current-voltage sweeps can be used to determine the percentages of $\mathrm{O}^{+}$and light ion species $\left(\mathrm{H}^{+}\right.$and $\left.\mathrm{He}^{+}\right)$. Because of the large sensitivity of in-track velocity measurements to uncertainties in the spacecraft potential, RPA estimates of in-track velocity often have large error bars and are not used here. We use $1 \mathrm{~s}$ averages of the horizontal cross-track plasma drifts in this study for all the DMSP satellites, except F15 for which we have 4 s averages of plasma drifts available.

SSM sensors are triaxial fluxgate magnetometers that are mounted on $5 \mathrm{~m}$ booms on the F15-F18 spacecraft. Magnetic vectors are sampled 12 times per second. One second average values are calculated as $\mathrm{d} B=B_{\text {meas }}-B_{\mathrm{IGRF}}$ the differences between measured and International Geomagnetic Reference Field (IGRF) values of magnetic fields at the spacecraft locations. Data are presented as $\mathrm{d} B_{X}, \mathrm{~d} B_{Y}$, and $\mathrm{d} B_{Z}$ in spacecraft-centered coordinates. The $X$ and $Y$ axes point toward spacecraft nadir and along the velocity vector, respectively. The $Z$ axis completes the right-hand system. Nearly simultaneous observations from the SSM and SSIES sensors on the various DMSP spacecraft help corroborate and interpret electrodynamic measurements in the storm's main phase. Velocity and magnetic field observations are combined to calculate Poynting flux, as described below.

Neutral densities on the GRACE satellite were measured using superSTAR accelerometers, using the techniques of
Sutton et al. (2005) and Sutton (2009). These measurements are similar to those made by the STAR accelerometer on CHAMP (Sutton 2009; Bruinsma et al. 2014), with a precision an order of magnitude greater than the CHAMP instrument. During the period of interest, the satellite is in a $451 \times 481 \mathrm{~km}$ orbit, with inclination of $89^{\circ}$ and average altitude of $470 \mathrm{~km}$. For our study the data were averaged in bins of $3^{\circ}$ in latitude, approximately $45 \mathrm{~s}$ of data.

Gravity field and steady-state Ocean Circulation Explorer (GOCE) operated from March 2009 through October 2013 in a near-circular, sun-synchronous orbit at an inclination of $96.5^{\circ}$ and an average altitude of $275 \mathrm{~km}$ during the interval of our three selected storms. Six 3-axis accelerometers enabled high-resolution mapping of the Earth's gravity field. Thruster activations maintained the satellite in its low altitude orbit by compensating for atmospheric drag. Neutral densities were extracted from a combination of ion propulsion and accelerometer data (Bruinsma et al. 2014). In this study we use the 10 -s resolution data available through the European Space Agency website (https://earth.esa.int/web/guest/-/goce-dataaccess-7219).

\subsection{Solar wind conditions}

Figure 1 shows the solar wind conditions for the three storms presented here. The first storm onset occurred on August 5, 2011 and was the subject of our earlier paper on the energy budget (Huang et al. 2014a). We take the end of the main phase (MP) to be at the minimum in Sym H at 0327 UT, or Day of Year (DOY) 218.14.

Solar wind dynamic pressure and Interplanetary Magnetic Field (IMF) for the September 2011 storm are shown in the middle panels of Figure 1, with storm onset at DOY 269.53 indicated by the red dotted line. The end of the MP occurs at DOY 269.89 .

The January 2012 storm period is shown in the last panels of Figure 1, with storm onset at DOY 22.33 shown by the vertical red dotted line, and the end of the MP at DOY 23.21.

These three storms were selected on the basis of data availability, not specific solar wind conditions. The observed IMF and dynamic pressure are simply what was measured on these days. The IMF shows large oscillations in all three components, but $B_{z}$ is negative during most of the main phase. The dynamic pressure is typically large at the storm onset, and can be large during most of the main phase. We regard these conditions as typical of most storms triggered by Coronal Mass Ejections (CMEs), and their effect on the IT system as typical of solar wind forcing. We have expanded our analysis to include an additional 40 storm intervals, of which the three discussed in this paper are generally representative.

\subsection{Ionospheric response to solar wind forcing - Observations}

Energy input into the ionosphere during magnetic storms is twofold: particle precipitation and Poynting flux, or electromagnetic waves. The effects of particle precipitation have been reported for decades - auroral emissions, intense field-aligned currents, enhanced conductivity are examples, but only relatively recently has the relative contribution of particle energy to the total storm energy budget been estimated. In a comparison of particle precipitation with solar radiation and Joule heat, Knipp et al. (2004) arrived at a ratio of particle to Joule heat of approximately 1:10 for large storms. In our study of the August 2011 storm, we estimated the precipitation power as 

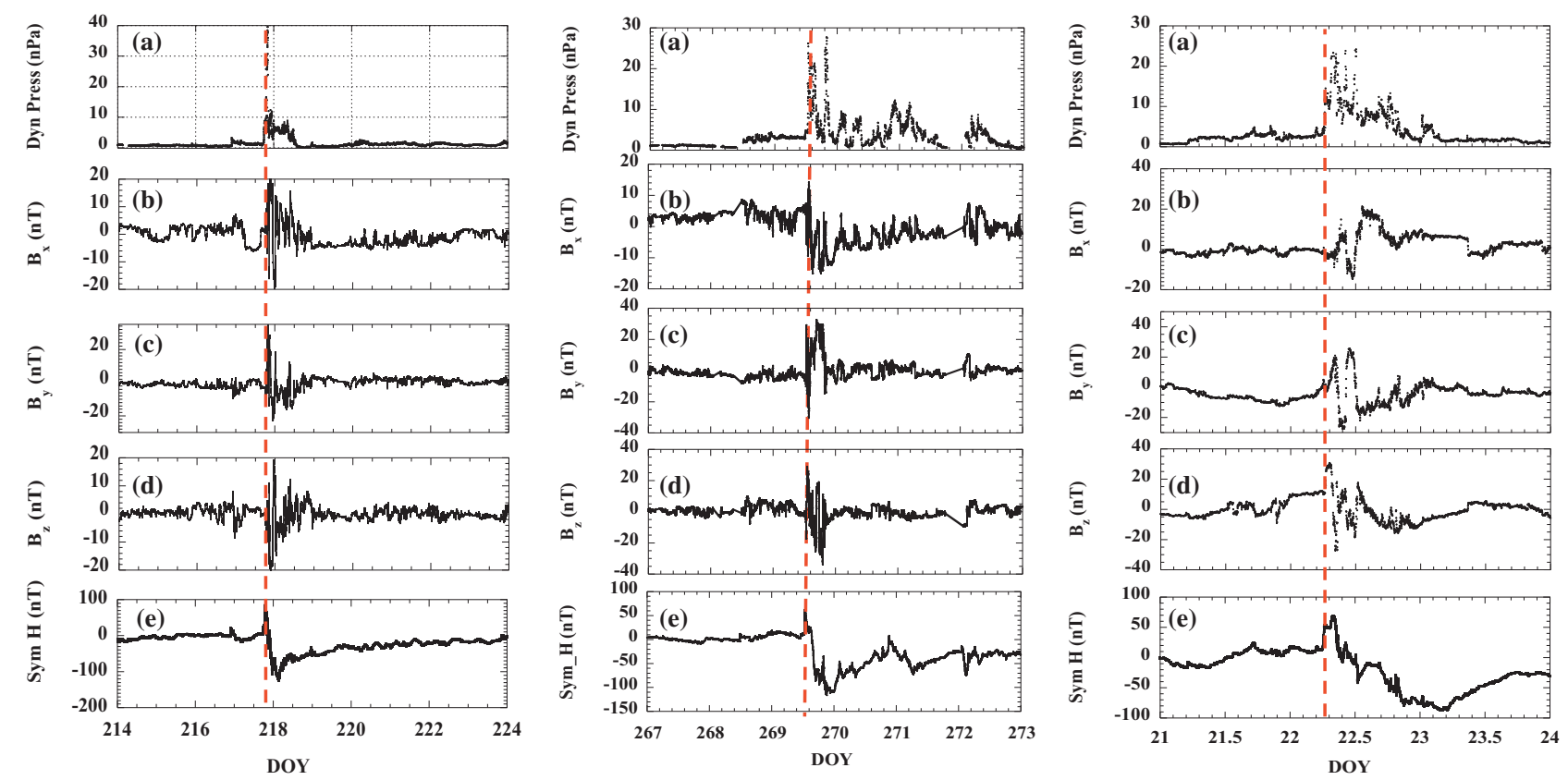

Fig. 1. Solar wind, IMF, and storm indices for the three magnetic storms in this study: August 5-6, 2011 (left), September 26,2011 (center), January 22, 2012 (right). From top to bottom are shown: (a) dynamic pressure; (b) $B_{x}$; (c) $B_{y}$; (d) $B_{z}$; (e) Sym $H$ index. Red dashed lines demarcate the times of onset of activity.

well as the observed Poynting flux and reached similar ratios (Huang et al. 2014a). It is clear that Poynting flux is the dominant form of energy input to the IT system. If electromagnetic waves are the main source of energy, any thermospheric response to a magnetic storm must necessarily involve energization of ions, since neutrals cannot be energized directly by electromagnetic waves. Thus IT coupling is central to any understanding of thermospheric variations during storms.

Poynting fluxes have been calculated for the ionosphere for some time (Kelley et al. 1991; Huang \& Burke 2004; Wilder et al. 2012; Cosgrove et al. 2014). DMSP routinely measures the ion drifts from which the convective electric field $(E)$ can be extracted, as well as magnetic perturbations $(\delta B)$ about the Earth's magnetic field. From $E$ and $\delta B$ the Poynting flux, $S=E \times \delta B / \mu_{0}$ where $\mu_{0}$ is the magnetic permeability of free space, can be calculated. We follow the methodology outlined by Huang \& Burke (2004) for all the DMSP spacecraft with data for the three storms selected for study.

In this study, we separate the open/closed field line regions using the direction of the cross-track horizontal velocity as our working definition of the Convection Reversal Boundary (CRB). This does not exactly coincide with the limits of the polar cap since the low-latitude boundary layer (LLBL) can straddle the CRB while remaining on closed field lines (Newell et al. 1991). We use the CRB as an indicator of the separation between polar and auroral and sub-auroral regions for simplicity. The particle definitions of the different regions at high latitudes (Newell \& Meng 1992) can be problematic, particularly during storms when particle signatures show large variations. We have found no clear features which can be associated with the LLBL in our analysis of energy input and output. Thus the CRB provides a direct, relatively unambiguous empirical definition of the polar cap.

Figure 2 shows a plot of measured Poynting fluxes during the main phase of the August 2011 storm. The orbital tracks from DMSP F15, 16, and 18 are shown with the maximum measured values plotted on top of lower values at the same locations. The Northern hemisphere results are shown in Figure 2a. The Southern hemisphere results are shown in Figure $2 \mathrm{~b}$. Figures $2 \mathrm{c}$ and $2 \mathrm{~d}$ display the Poynting flux integrated along the DMSP satellite track for the polar cap (in red), the auroral zones from the $\mathrm{CRB}$ to $50^{\circ}$ Magnetic latitude (Mlat) (in blue), and the total (in black) for Northern and Southern hemispheres, respectively. In Figures $2 \mathrm{e}$ and $2 \mathrm{f}$ the percentages of the total integrated Poynting flux along the DMSP track measured inside the polar cap are demonstrated for the Northern and Southern hemispheres, respectively.

Figure 3 shows similar plots of measured Poynting fluxes for the September 2011 and January 2012 magnetic storms. In Figures $3 \mathrm{a}$ and $3 \mathrm{~b}$ the Northern and Southern hemisphere results are shown for the September 2011 storm. The same format is used in Figures 3c and 3d for the January 2012 storm.

One measurement illustrating energy output is the ion temperature, $T_{\mathrm{i}}$, which we take as a proxy for Joule heating. We assume that Joule heating of ions occurs at some altitude where conductivity is relatively large. For the auroral zone, Hall conductivity typically peaks at $E$-layer altitudes, around $100-120 \mathrm{~km}$. In the polar cap where particle precipitation is soft, the ionization due to electrons measured during an interval in the August 2011 storm peaks at 250-300 km (Huang et al. 2014b). Lacking a monitor close to these altitudes, we use the measured ion temperature, $T_{\mathrm{i}}$ from DMSP, keeping in mind that $T_{\mathrm{i}}$ at these altitudes may be affected by physical processes which occur during the storm.

In Figure 4 we show the measured $T_{\mathrm{i}}$ during the pre-storm quiet period for the three storms in our study. Data have been averaged in bins of $2^{\circ}$ Mlat $\times 1 \mathrm{~h}$ of Magnetic Local Time (MLT) in the Altitude Adjusted Corrected Geomagnetic (AACGM) coordinate system (Baker \& Wing 1989). Along the top row are shown the measured values of $T_{\mathrm{i}}$ for the interval preceding storm onset for the Northern Hemisphere. This interval is shown in Figure 1 from the start of each figure to the time of storm onset. The bottom row shows results in the same format for the Southern hemisphere. Figures $4 \mathrm{a}$ and $4 \mathrm{~b}$ are for 

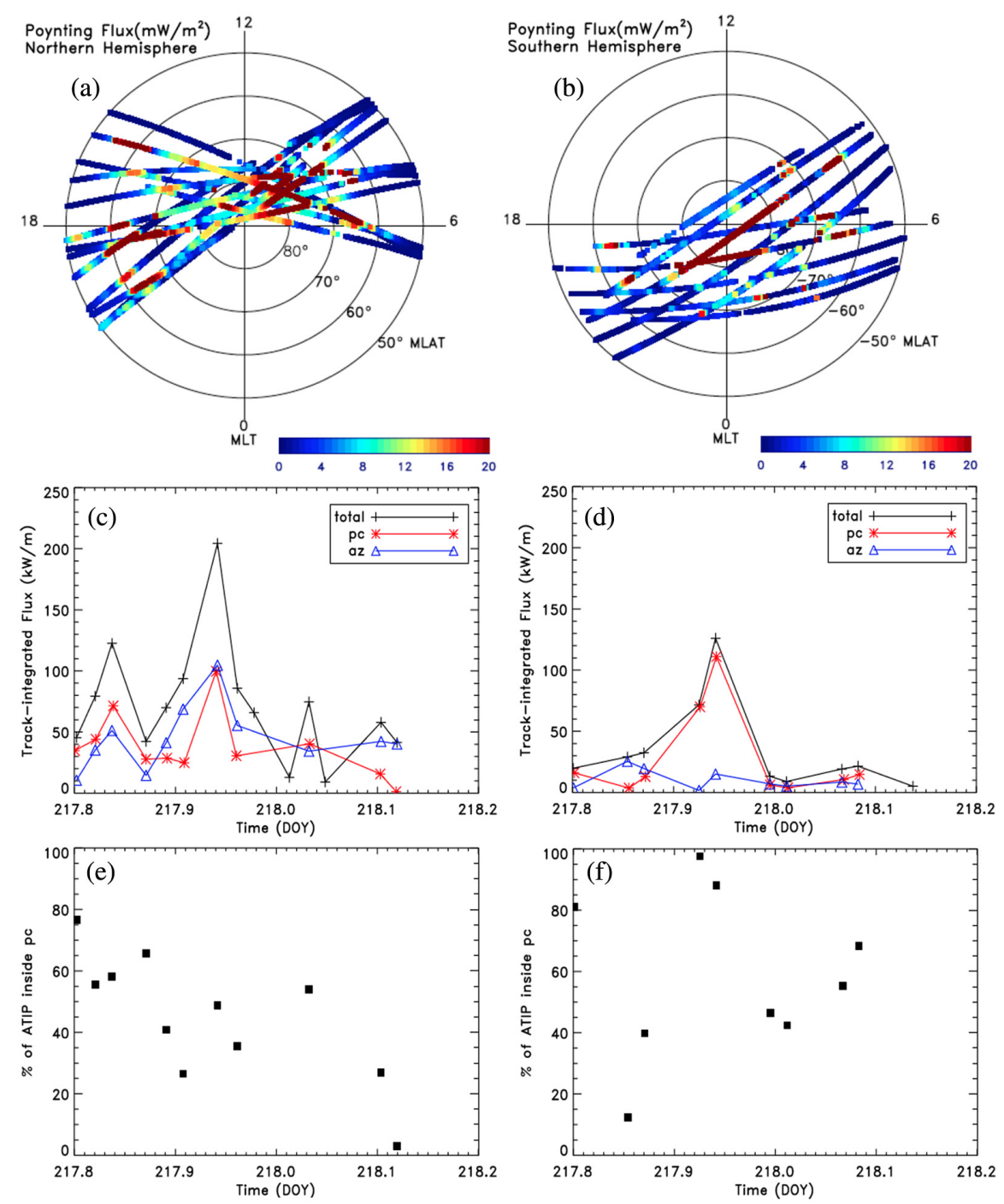

Fig. 2. Poynting fluxes overplotted for the August 2011 magnetic storm. (a) Northern Hemisphere (NH) (left); (b) Southern Hemisphere (SH) (right); (c) NH Poynting flux integrated along the satellite track, with polar cap contribution (red), auroral zone contribution (blue), and total (black); (d) SH Poynting flux in same format as (c); (e) percentage of track-integrated Poynting flux in the polar cap in the NH; (f) SH percentage of track-integrated Poynting flux.

the August 2011 pre-storm period; Figures 4c and 4d show the September time interval, and Figures $4 \mathrm{e}$ and $4 \mathrm{f}$ correspond to the January 2012 interval. The magenta squares and triangle mark the CRBs determined from the DMSP horizontal velocities.

Figure 5 shows the bin-averaged change in $T_{\mathrm{i}}$ during the storm, $\Delta T_{\mathrm{i}}=T_{\mathrm{i}}$ (main phase) $-T_{\mathrm{i}}$ (quiet) in the same format as Figure 4. This plot illustrates the locations and intensity of Joule heated ions at DMSP altitudes for three storms. It is commonly assumed that storm energy is dissipated as Joule heat of ions and neutrals (Weimer 2005). Since Poynting flux cannot interact directly with neutrals, ions are a means of energy transfer from incoming Poynting flux to neutrals.

Details of the variations in $T_{\mathrm{i}}$ during the storm are illustrated in Figure 6 which shows crossings of both Northern and Southern polar caps during the main phase of the August 2011 storm. The data are from DMSP F16 and both the horizontal velocity, $V_{\mathrm{h}}$ (black) and ion temperature, $T_{\mathrm{i}}$ (blue) are shown. The four panels show measured $V_{\mathrm{h}}$ and $T_{\mathrm{i}}$ for the first four orbits following storm onset at 19:06 UT. The times of the polar crossings are noted at the top left of each panel. Note that the $V_{\mathrm{h}}$ data quality is shown as black (good), yellow (use with caution), red (poor), and aqua (undetermined). In our analysis, we only use data rated as good or use with caution. For $T_{\mathrm{i}}$, we only use data rated as good.

In the panels, it can be seen that the sunlit Northern hemisphere data are generally of higher quality than the Southern hemisphere which is in darkness for most of these four orbits. However, two features appear in these polar crossings. First, $T_{\mathrm{i}}$ is generally higher in the polar cap where $V_{\mathrm{h}}$ is antisunward than in the adjoining regions with sunward $V_{\mathrm{h}}$. Second, immediately adjacent to the $\mathrm{CRB}, T_{\mathrm{i}}$ often decreases sharply. This is most evident in the Northern hemisphere plots for orbits labeled 1941, 2303, and 0046 UT.

Figure 7 shows orbital plots for the same four orbits as shown in Figure 6. In this figure, the measured $T_{\mathrm{i}}$ is shown plotted in red with maximum positive values toward the nightside from the orbit track, i.e. downward in each figure panel. The Poynting flux is shown in blue plotted with maximum positive values toward the dayside, i.e. upwards in each figure 
C.Y.-Y. Huang et al.: IT response to solar wind forcing
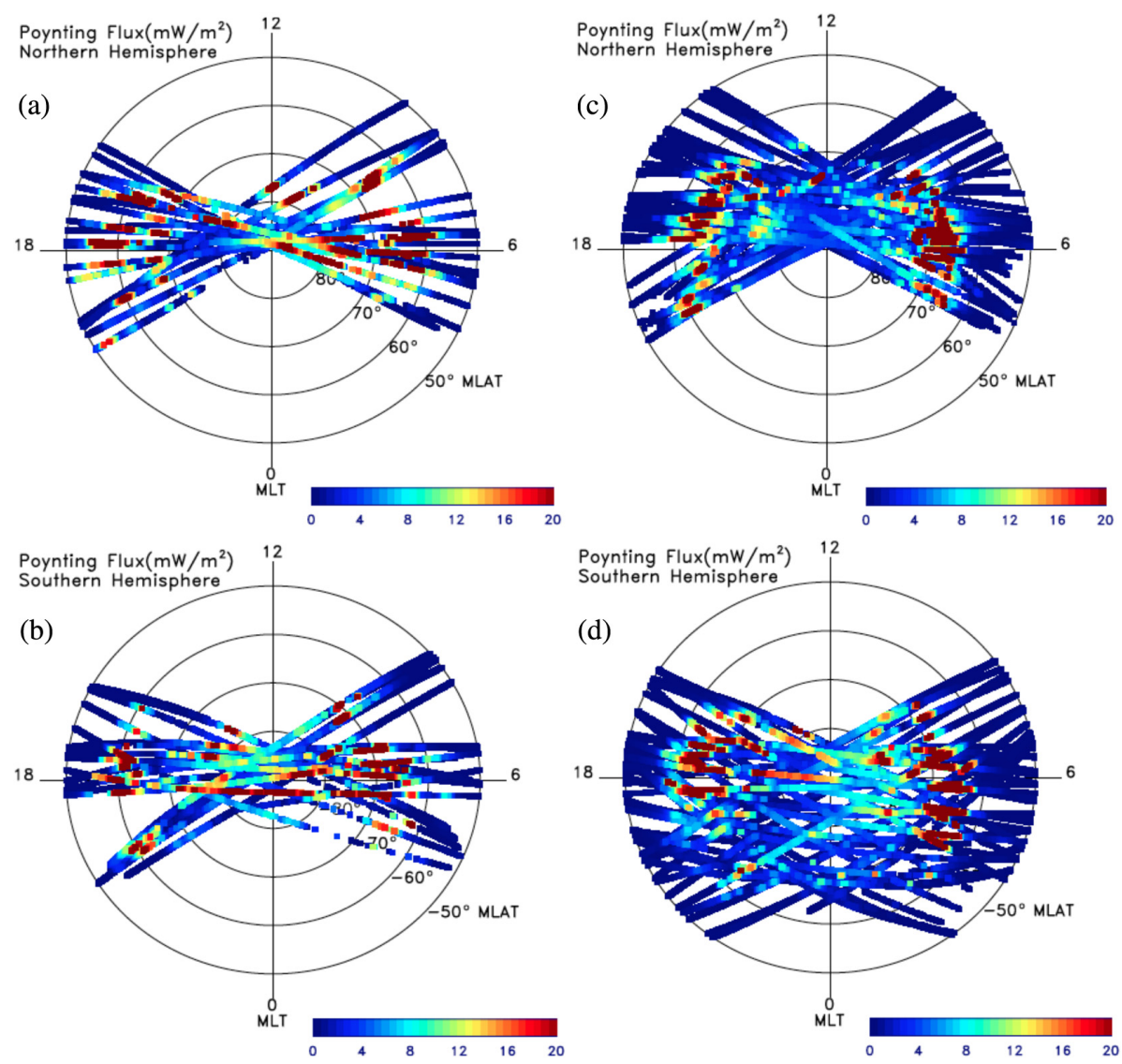

Fig. 3. Overplotted Poynting fluxes for the September 2011 storm (left), for the January 2012 storm (right). At top are shown the NH results, with $\mathrm{SH}$ measurements below.
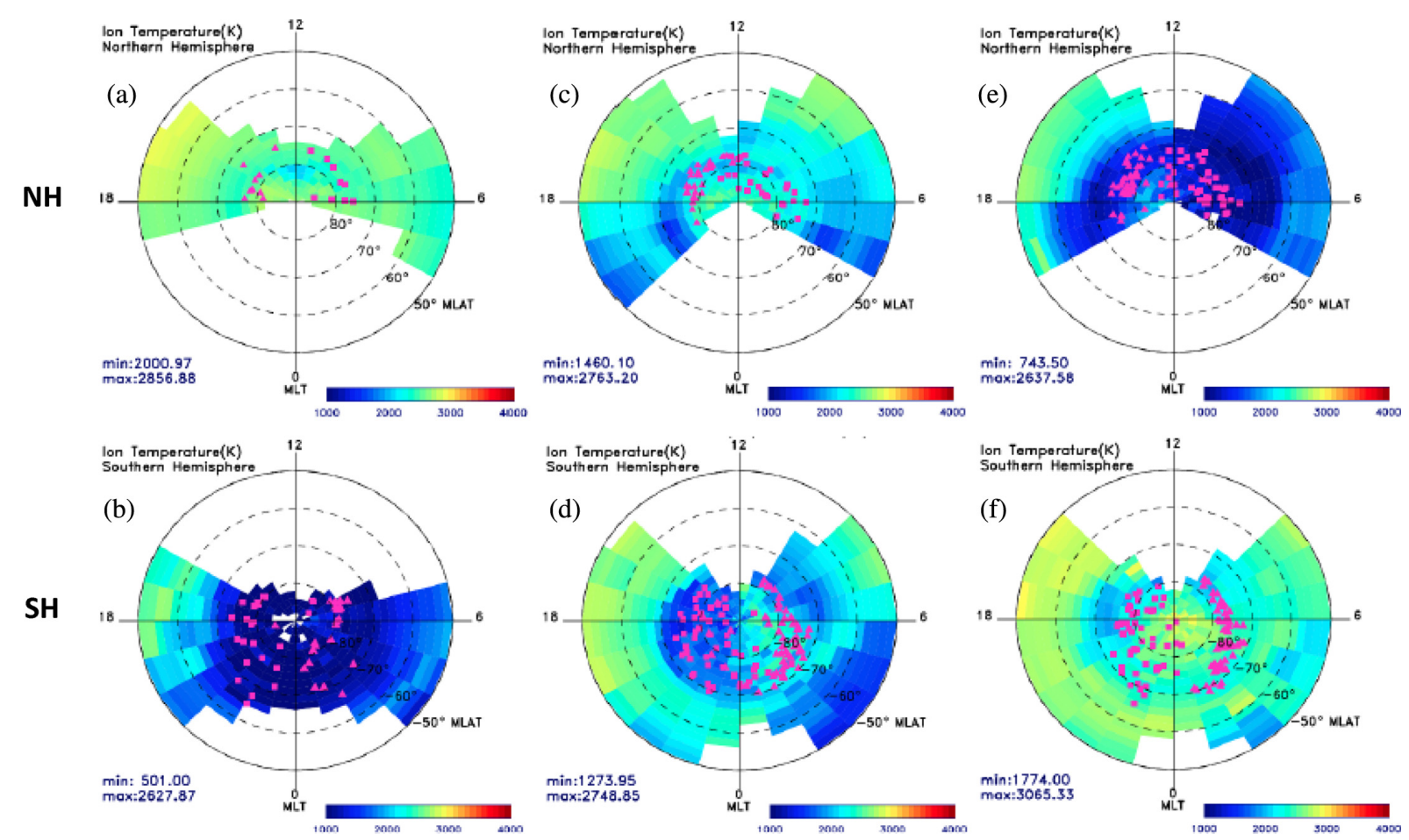

Fig. 4. Measured bin-averaged $T_{\mathrm{i}}$ from DMSP for the pre-storm quiet period for three storms. The results for August 2011 (a, b, left); September 2011 (c, d, middle); January 2012 (e, f, right) storms are shown. At top are the NH observations (a, b, c), with SH results below $(\mathrm{d}, \mathrm{e}, \mathrm{f})$. The magenta triangles and squares illustrate the locations of convection reversal boundaries along DMSP paths. 

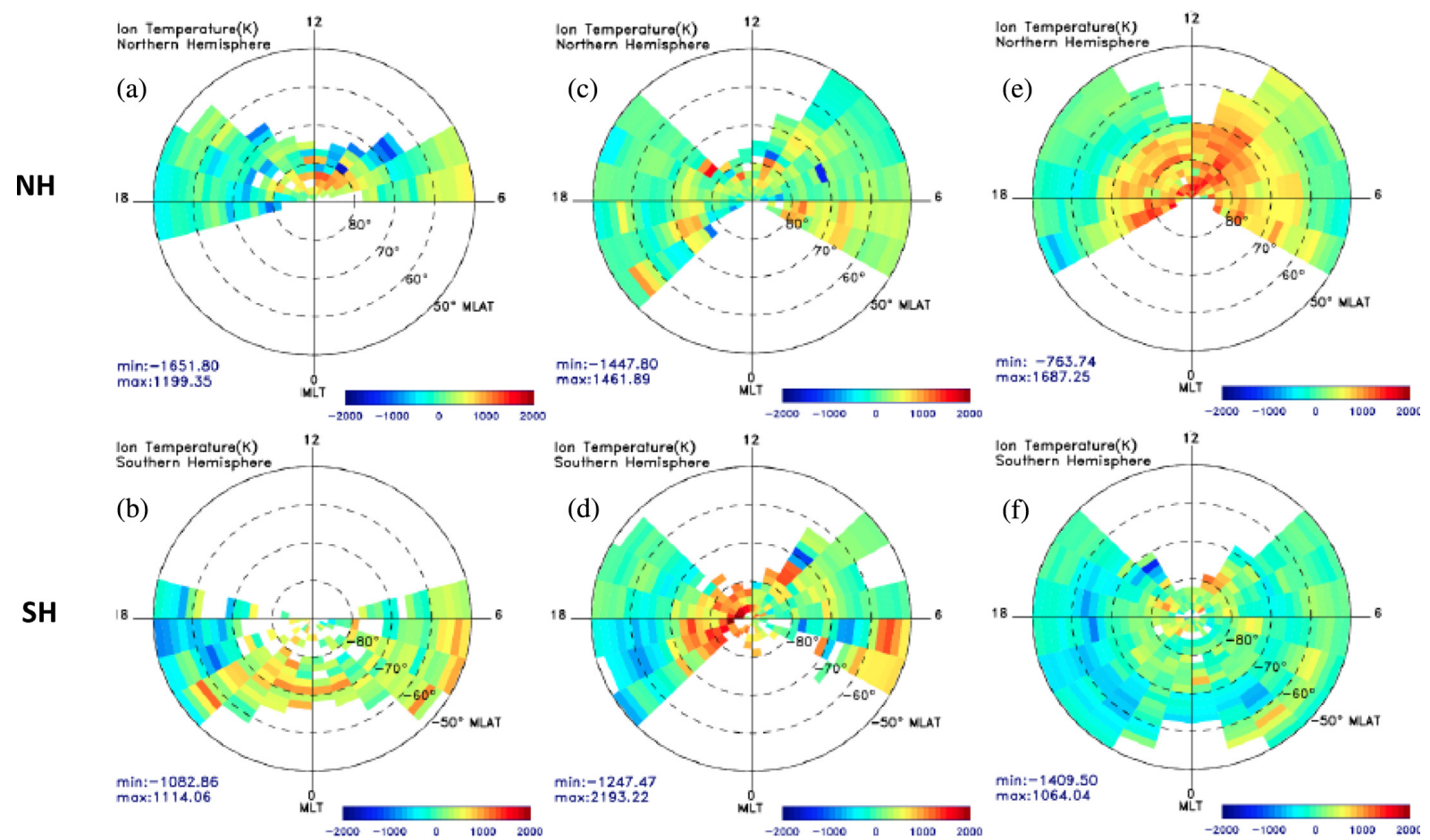

Fig. 5. Measured bin-averaged $\Delta T_{\mathrm{i}}$ from DMSP for three storms. The results for August 2011 (a, b, left); September 2011 (c, d, middle); January 2012 (e, f, right) storms are shown. At top are the NH observations (a, c, e), with SH results below (b, d, f).

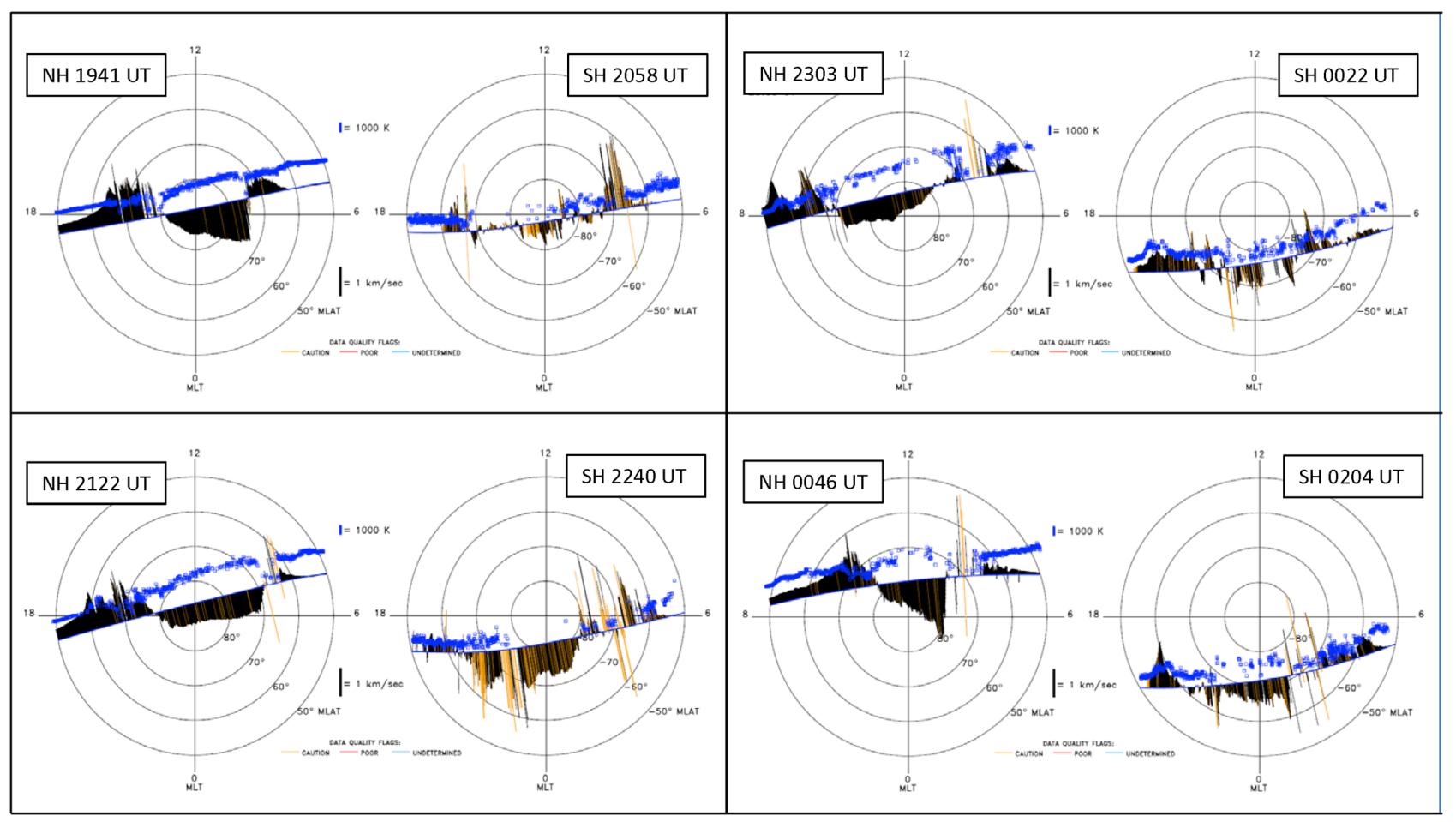

Fig. 6. DMSP F16 observations of horizontal velocity and ion temperature, $T_{\mathrm{i}}$ (red), shown for four orbits after storm onset at $1906 \mathrm{UT}$ on 5 August 2011. Scales for $V_{\mathrm{h}}$ and $T_{\mathrm{i}}$ are shown in each panel. The horizontal velocity is plotted in different colors corresponding to the data quality which can be good (black), use with caution (yellow), poor (red), and undetermined (aqua).

panel. Scales for $T_{\mathrm{i}}$ and $S_{\mathrm{x}}$ are shown to the right of each NH crossing. The CRBs in this figure are shown by vertical gray lines perpendicular to the orbit track. The hemisphere is indicated for each orbital crossing, with the time listed of the highest latitude reached by DMSP F16 during the polar pass. Note that where data quality was insufficient, there are gaps.

\subsection{Thermospheric response to solar wind forcing - observations}

The primary observation of thermospheric response to stormtime energy input is an increase in neutral density at a fixed altitude. We will use this as a marker of Joule heating during 


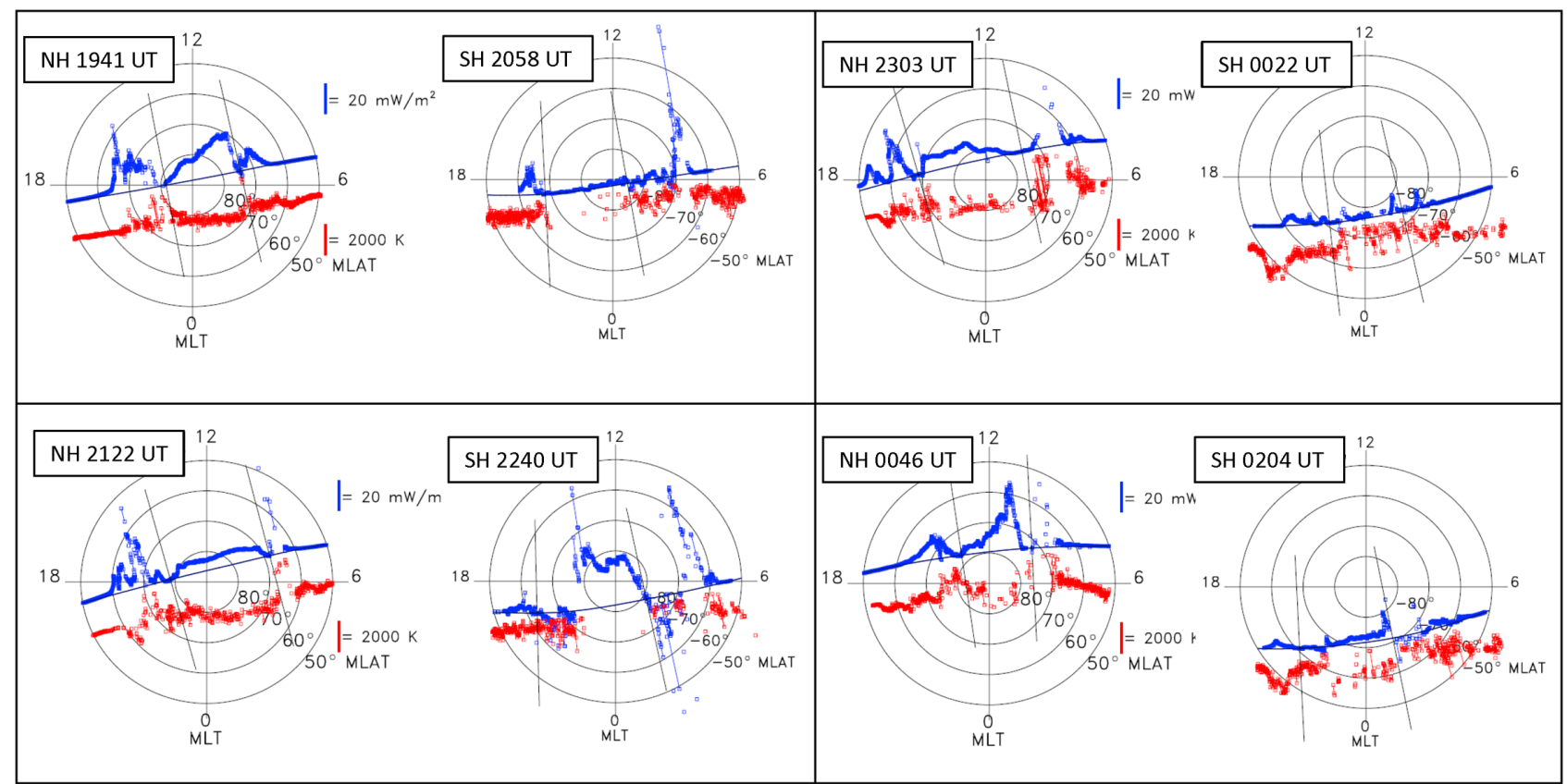

Fig. 7. DMSP F16 observations of Poynting flux (blue) and ion temperature, $T_{\mathrm{i}}$ (red) along the satellite orbit track for the same four orbits as shown in Figure 6. Poynting flux is plotted with maximum positive values toward the dayside, i.e. upward from the orbit track. $T_{\mathrm{i}}$ is plotted with maximum positive values toward the nightside, i.e. downward from the orbit track In each panel, the hemisphere and time of F16 crossing the highest latitude are indicated at top left. The location of the CRBs is shown by gray lines perpendicular to the orbit track. The scale for Poynting flux and $T_{\mathrm{i}}$ are shown to the right of each $\mathrm{NH}$ panel.
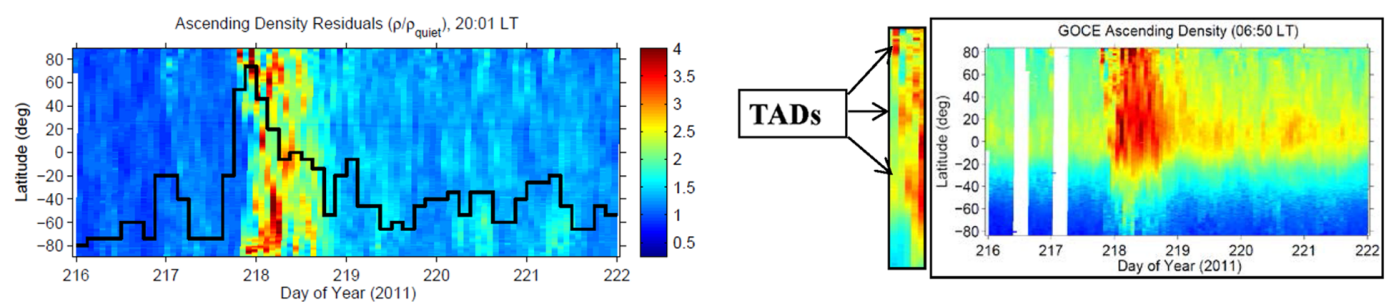

Fig. 8. Neutral densities from GRACE at 20:01 LT (left) and GOCE at 06:50 LT (right) as functions of time along the $X$ axis, and latitude along the Yaxis, measured during the August 2011 magnetic storm. At left, the GRACE data are shown as residuals $\left(\rho / \rho_{\text {quiet }}\right)$, with $K_{\mathrm{p}}$ shown as the heavy black line. TADs were reported in the GRACE data (Huang et al. 2014a). The inset to left of the GOCE data panel is an expanded view of the initial response to the storm onset. The higher densities (in red) indicated by arrows are detected at decreasing latitude at later times, corresponding to the TAD.

our storm intervals. As noted in our earlier study of the August 2011 storm, Traveling Atmospheric Disturbances (TADs; Bruinsma \& Forbes 2007) were observed in the accelerometer data from the GRACE satellite (Huang et al. 2014a). TADs are gravity waves generated by Joule heating. By using both GRACE $\mathrm{A}$ and $\mathrm{B}$ observations, we were able to show that TADs propagated from polar to equatorial latitudes in both hemispheres at approximately 20 LT.

During the August 2011 storm, TADs were also observed on the GOCE satellite at 0650 LT. Figure 8 shows the simultaneous TADs from GRACE and GOCE. In both cases the TADs propagate from pole to equator, implying that Joule heating occurs poleward of $83^{\circ}$ Mlat (GRACE) at 2001 LT and poleward of $75^{\circ}$ Mlat (GOCE) at $0650 \mathrm{LT}$.

In Figure 9, the densities from the two spacecraft have been normalized to a constant altitude of $470 \mathrm{~km}$ (GRACE) and $275 \mathrm{~km}$ (GOCE) using the NRLMSISE 2000 model (Picone et al. 2002). The densities (in black) and satellite magnetic latitudes (in red) are shown as functions of Day of Year (DOY) through the onset and main phase of the storm. Two results are apparent in this figure: (1) the largest increases in neutral density at both spacecraft occur at high latitudes; (2) there are real differences in thermospheric responses at the two locations, separated by approximately $200 \mathrm{~km}$ in altitude. It is beyond the scope of this report to describe the features in detail, but it appears that the overall trend at GRACE is more variable than that at GOCE, which may reflect the differences in ambient densities. What appears clear is that there is an initial localized spike in density at high latitude, followed by a series of smaller increases in density at lower latitudes on subsequent revisits of the polar region. The lower-latitude maxima may be the TADs shown in Figure 8. Overall there is a gradual rise in density levels at both satellites, but this rise consists of multiple localized maxima which proceed from high to low latitudes. We have compared the orbit-averaged densities, which include all temporal variations shown in Figure 9, with that estimated independently using the High Accuracy Satellite Drag Model (HASDM; Casali \& Barker 2002; Storz et al. 2002) and find good overall agreement for both GRACE and GOCE measurements. 


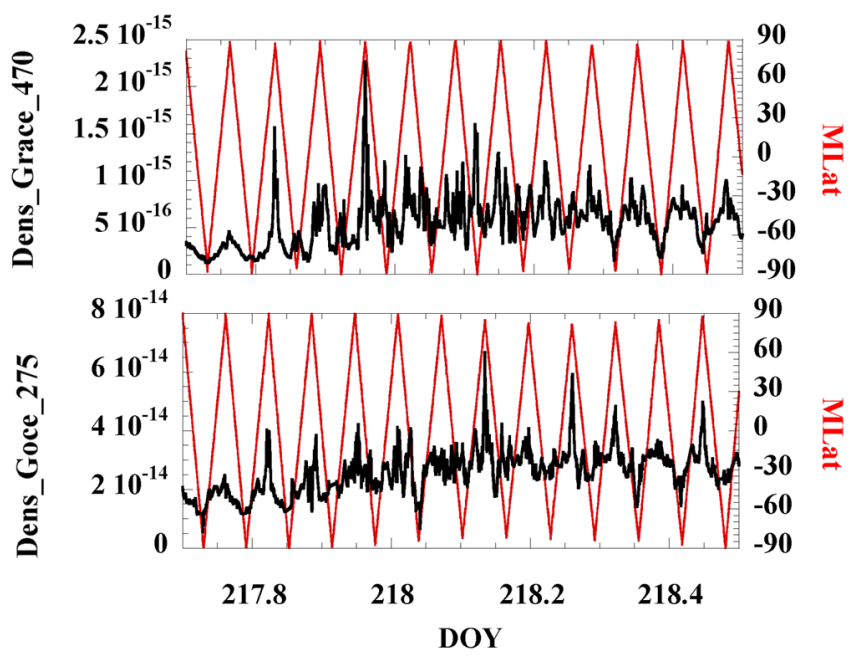

Fig. 9. GRACE (top) and GOCE (bottom) neutral densities scaled to fixed altitudes of $470 \mathrm{~km}$ (GRACE) and $275 \mathrm{~km}$ (GOCE) during the August 2011 magnetic storm which began at Day of Year (DOY) 217.8. The magnetic latitudes of both spacecraft are shown in red. The largest density maxima measured during the storm occur at the highest latitudes throughout the main phase.

We extract the maxima in neutral density by fitting a moving smooth curve over consecutive data. For GRACE the interval spans 30 points, or about $22.5 \mathrm{~min}$. For GOCE the interval is 150 points, or approximately $25 \mathrm{~min}$. Neutral densities greater than a set threshold $\left(5.0 \times 10^{-16} \mathrm{~g} \mathrm{~cm}^{-3}\right.$ for GRACE and $2.5 \times 10^{-14} \mathrm{~g} \mathrm{~cm}^{-3}$ for GOCE) and $30 \%$ above the curve are designated as maxima. In Figure 10 we show the energy flow during the August 2011 storm, with the increase in binaveraged average Poynting flux at left, the measured change in ion temperature $\left(\Delta T_{\mathrm{i}}\right)$ at center, and the maxima in the measured GRACE neutral densities at right with gray crosses indicating the satellite trajectory. The top row shows all the data for the Northern hemisphere, with the Southern hemisphere shown below.

Figure 11 shows the maxima, selected as described above, measured by GRACE during 2011 (left) and the first half of 2012 (right) (all the 2012 data available at this time). In this figure, the threshold is $30 \%$ above the average fitted curve. The satellite orbit is shown by gray crosses. In 2011, orbital coverage included all local times. In 2012, there were local times not covered during the 6 months of available data. Plotted on top are the Northern hemisphere data, below are the Southern hemisphere data. The results show clusters of points at high latitudes similar to the results of Liu et al. (2010) who carried out a study of neutral densities during selected magnetic storms. There is no discernible auroral zone in the neutral density maxima in the GRACE or GOCE data during 2011 and 2012.

Similar results have been obtained from remote sensing of the $\mathrm{O} / \mathrm{N}_{2}$ ratio from GUVI and SSUSI on the TIMED and DMSP satellites, respectively. As the thermosphere is heated, upwelling of the atmosphere lifts oxygen-depleted or nitrogenrich air from lower in the atmosphere into the $\mathrm{F}$ region (Mayr \& Volland 1972; Prolss 1980). This change in composition can be observed in the ultraviolet (UV) images which correspond to altitudes from 135 to $200 \mathrm{~km}$ (Zhang et al. 2004). The depleted areas proceed from polar to lower latitudes during storms, including the August 5-6, 2011 event (Y. Zhang, priv. comm. 2014).
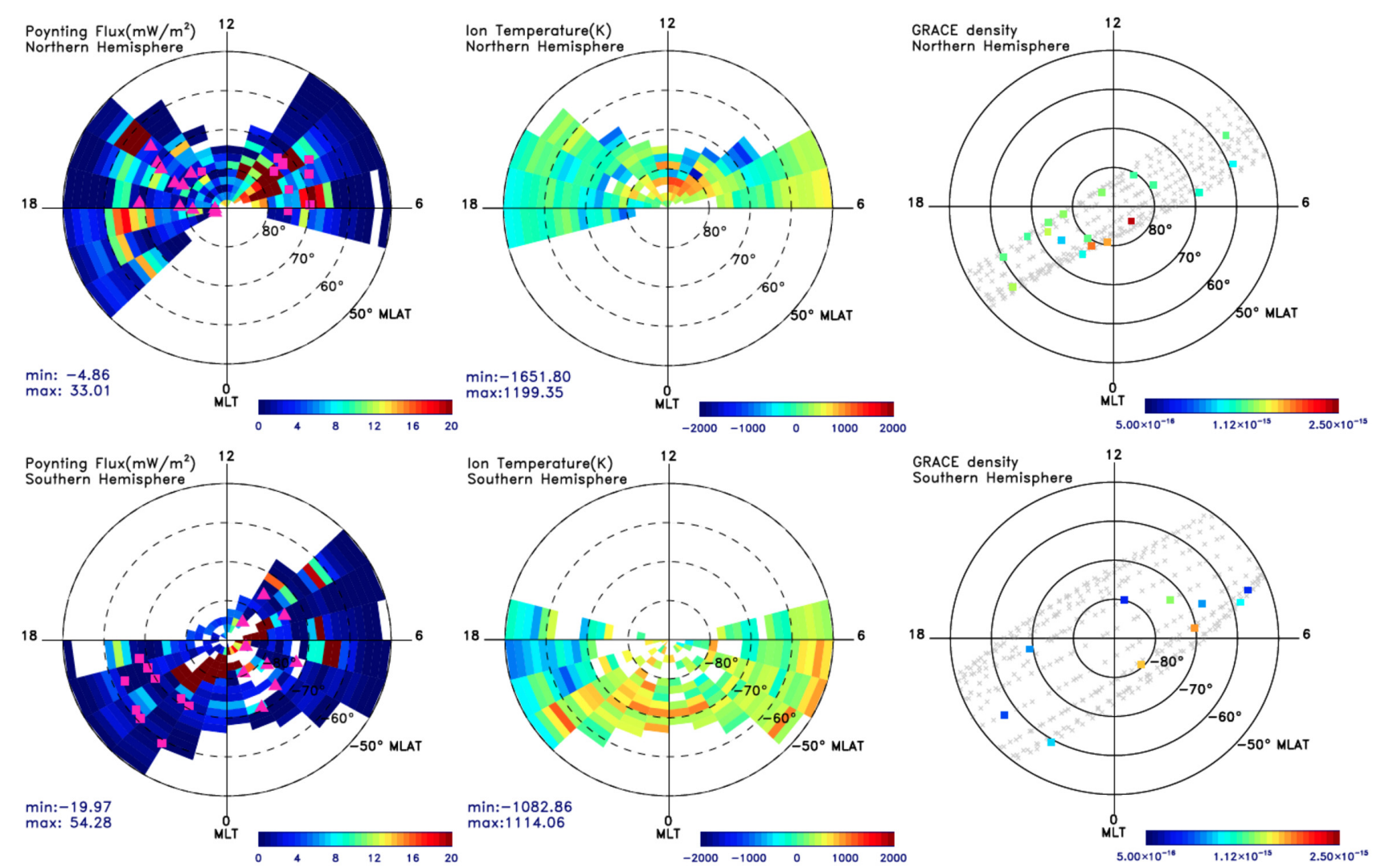

Fig. 10. DMSP bin-averaged Poynting flux (left), $\Delta T_{\mathrm{i}}$ (middle), and GRACE density maxima (right) for the August 2011 storm, NH data above, SH data below. 

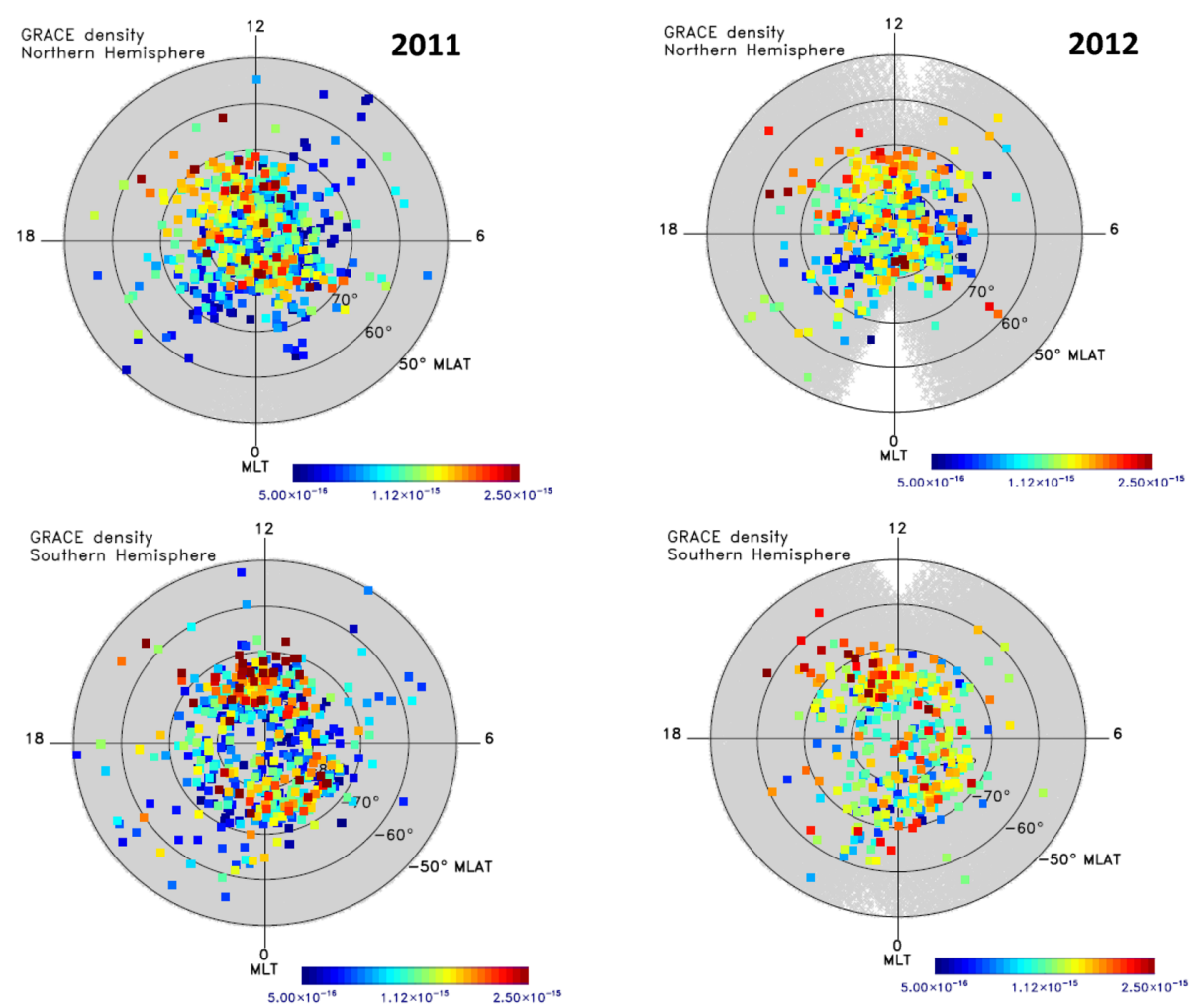

Fig. 11. GRACE density maxima $\left(\rho / \rho_{\text {avg }}\right)>1.3$ for 2011 (left) and the first half of 2012 (right), NH data above, SH data below. Satellite orbit locations are indicated by gray crosses.

\section{Discussion}

We have presented DMSP, GRACE, and GOCE observations during three magnetic storms which occurred in August and September 2011, and January 2012. Poynting flux calculated from DMSP measurements of convective electric and magnetic fields show clear maxima at polar as well as auroral latitudes in every case, at all local times. During the August 2011 storm, the highest Poynting fluxes occur on the nightside of the polar cap in the Southern hemisphere. In Figures $2 \mathrm{e}$ and $2 \mathrm{f}$, the percentage of Poynting flux entering the polar cap is significant in both hemispheres during the main phase. In the Northern hemisphere, the percentage ranges from $2.9 \%$ late in the main phase to $76.7 \%$ shortly after onset. The average during the storm main phase is $44.7 \%$ In the Southern hemisphere the range is $12.4 \%-97.7 \%$ with an average of $59.1 \%$. It is clear that electromagnetic energy, the primary form of solar wind energy input during storm events, can enter the IT system at all local times, and is not restricted to the cusp or auroral zones. This is a completely new result, at odds with the standard paradigm that all energy input to the IT system is restricted to the cusp and/or auroral zones.

The widely accepted paradigm is documented in papers by Weimer (2005), Cosgrove et al. (2014), McHarg et al. (2005), and others, in which the auroral zones and cusp dominate highlatitude energy input. The main reason for the discrepancy between our results and previous work lies in the way the data have been treated. In general, observations of Poynting flux, Joule heat, and other forms of energetic response are averaged to yield an empirical result. As pointed out by Cosgrove et al. (2014), this results in a "smearing" of the data. This kind of analysis brings out large-scale, steady-state phenomena but it does not represent well highly dynamic events like magnetic storms. For these reasons we emphasize individual near-instantaneous measurements of Poynting flux, ion temperature, and neutral densities in Figures 2, 3, 8, and 9 in which the high-latitude response can be easily seen. Upon averaging, the "smearing" effect reduces the appearance of high-latitude energy input which can be seen by comparing the plots of Poynting flux in Figure 2 with those in Figure 10. If we were to include all data under all conditions, the effect of averaging would reduce the dynamic high-latitude energy input further, giving the misleading impression that energy does not enter the polar cap.

We have also shown the effect of energy input into the IT system in the form of ion temperatures (a proxy for ion Joule heating) and neutral densities (and by implication, neutral temperatures). The ion temperatures measured at the DMSP spacecraft show clearly that there are maxima at polar latitudes prior to any magnetic activity. The polar cap is frequently warmer than the adjoining auroral zone. After the onset of activity, polar cap temperatures increase while auroral zone temperatures can remain relatively unchanged as in the August 2011 case.

The polar plots of Poynting flux, ion temperature, and neutral density maxima shown in Figure 10 illustrate the challenge in forecasting the effect of magnetic storms on the IT system. There are clear differences between the Poynting flux and the ion temperature, implying that there are differences between Poynting flux and Joule heat (Richmond 2010). The discrepancy between Poynting flux and measured $T_{\mathrm{i}}$ is even sharper in the January 2012 event (not shown). We have examined altitude profiles in the $F$ region of ion temperature using the TIEGCM model and do not find large variations in ion temperature as a function of altitude from 200 to $500 \mathrm{~km}$. Further, it is hard to discern a clear auroral zone in the ion temperatures in 
Figure 10, calling into question the assumption that Joule heat peaks at auroral latitudes. This conclusion is true of the three events presented here, as well as for several other cases we have studied.

The final piece of evidence that the polar cap must be integral to any treatment of IT response to solar wind forcing comes from the neutral density data from GRACE at an average altitude of $470 \mathrm{~km}$, and GOCE at an average altitude of $275 \mathrm{~km}$ during the three storms in this study. As can be seen in Figures 9 and 11, the dynamic response of the thermosphere appears as localized maxima restricted to the highest latitudes, i.e. the polar cap. It should be noted that there is a difference between the localized response and the global thermospheric response. We have reported earlier on the global response which takes place on time scales comparable to that of Sym $H$ during the main phase (Burke et al. 2007, 2010; Huang et al. 2008, 2014a), i.e. hours. In previous studies we employed the orbit-averaged response in thermospheric density to infer the global change. Here, we use the neutral density data as a function of latitude to determine where and when Joule heating of neutrals is first detected. In virtually every case, the large localized density maxima at storm onset occur at the highest latitudes reached by the spacecraft. The first sign of Joule heating is observed within minutes of the onset in the form of the large maxima, a very short time delay which is not explained in any current theory or model. On subsequent orbits, the density appears as series of peaks at lower latitudes, as the lower latitudes heat during the storm main phase. Typically the thermospheric response lasts as long as the main phase is indicated by Sym $H$, with orbit-averaged densities increasing during the entire time.

Heating of neutrals in the polar cap also appears in the ultraviolet images of the $\mathrm{O} / \mathrm{N}_{2}$ ratio from GUVI on the TIMED satellite, and SSUSI on DMSP. The $\mathrm{O} / \mathrm{N}_{2}$ ratio provides indirect information on Joule heating of atomic oxygen at altitudes of approximately 135-200 km (Zhang et al. 2004). The GUVI data for the August 2011 storm shows heated neutrals at the highest latitudes detectable by the instrument (Y. Zhang, priv. comm. 2014). After storm onset, the change in $\mathrm{O} / \mathrm{N}_{2}$ ratio moves from high to low latitude, similar to the spreading of neutral density maxima and propagation of TADs seen on GRACE and GOCE. Taken altogether, the accelerometer and UV imager data show that neutrals are heated at polar latitudes from 135 to $470 \mathrm{~km}$ in altitude during magnetically active periods.

The implications of our results are far-reaching. If the polar cap is the site of significant energy deposition and Joule heating of ions and neutrals, the assumptions common to most models of the IT system need to be modified. In the polar cap, the flux of precipitating particles is low, and particle energies are typically below $1 \mathrm{keV}$. This gives rise to low conductivities at F-layer altitudes, around $200-300 \mathrm{~km}$ (Huang et al. $2014 b$ ). At these altitudes, the ion-neutral collision rate is relatively low, and we expect ion drifts and neutral winds to result from high energy input.

By contrast in the auroral zones typical precipitating electron fluxes are high, with characteristic energies $\geq 1 \mathrm{keV}$, leading to high conductivity around $100 \mathrm{~km}$, in the E-layer. In the E-layer, the collision rate is relatively high, and we expect energy transfer to take place mainly through collisions. Given the large differences between the two regions, the result of large Poynting fluxes in the polar cap should have significantly different impact on the IT system.
A second area which deserves further study is the question of how high Poynting flux reaches the polar cap at local times (LTs) far from the cusp. It appears that energy from the solar wind can reach the ionosphere regularly during storms via the polar cap at all LTs. As the measured $T_{\mathrm{i}}$ as well as neutral densities also show increases in the polar cap during the storm main phase, we conclude that the incoming Poynting flux is effective in heating the ionosphere and thermosphere. The source of our observed Poynting flux is still unknown, as is the mechanism by which it enters the IT system and interacts with the polar cap plasma. These are questions which need to be addressed in order to improve our ability to forecast the effect of solar wind disturbances on the IT system.

Acknowledgements. We acknowledge the support of the Air Force Office of Scientific Research under Grants LRIR 14 RV11COR and FA9550-14-1-0280, and the National Science Foundation under Grant NSF Grant AGS-1259508. The authors wish to thank Dr. Daniel Ober and Dr. Gordon Wilson for providing DMSP magnetic field data. The OMNI data used in this study are available at the OMNIWeb interface (http://omniweb.gsfc.nasa.gov). The GOCE data are available through the European Space Agency website (https://earth.esa.int/web/guest/-/goce-data-access-7219<https:// earth.esa.int/web/guest/-/goce-data-access-7219>). The editor thanks Delores Knipp and an anonymous referee for their assistance in evaluating this paper.

\section{References}

Akasofu, S.-I. Energy coupling between the solar wind and the magnetosphere. Space Sci. Rev., 28, 121-190, 1981.

Baker, K.B., and S. Wing. A new magnetic coordinate system for conjugate studies at high latitudes. J. Geophys. Res., 94 (A7), 9139-9143, 1989, DOI: 10.1029/JA094iA07p09139.

Bruinsma, S.L., and J.M. Forbes. Global observation of traveling atmospheric disturbances (TADs) in the thermosphere. Geophys. Res. Lett., 34, L14103, 2007, DOI: 10.1029/2007GL030243.

Bruinsma, S.L., E. Doornbos, and B.R. Bowman. Validation of GOCE densities and evaluation of thermosphere models. Adv. Space Res., 54, 576-585, 2014, DOI: 10.1016/j.asr.2014.04.008.

Burke, W.J., C.Y. Huang, F.A. Marcos, and J.O. Wise. Interplanetary control of thermospheric densities during large magnetic storms. J. Atmos. Sol. Terr. Phys., 69, 279-287, 2007.

Burke, W.J., C.Y. Huang, D.R. Weimer, J.O. Wise, G.R. Wilson, C.S. Lin, and F.A. Marcos. Energy, power requirements of the global thermosphere during the magnetic storm of November 10, 2004. J. Atmos. Sol. Terr. Phys., 309-318, 2010, DOI: $10.1016 /$ j.jastp.2009.6.005.

Casali, S., and W. Barker. Dynamic Calibration Atmosphere (DCA) for the High Accuracy Satellite Drag Model (HASDM). AIAA2002-4888, AIAA/AAS Astrodynamics Specialist Conference and Exhibit, Monterey, California, 2002.

Cosgrove, R.B., H. Bahcivan, S. Chen, R.J. Strangeway, J. Ortega, M. Alhassan, Y. Xu, M. Van Welie, J. Rehberger, S. Musielak, and N. Cahill. Empirical model of Poynting flux derived from FAST data and a cusp signature. J. Geophys. Res., 119, 411-430, 2014, DOI: 10.1002/2013JA019105.

Coumans, V., J.-C. Gerard, B. Hubert, M. Meurant, and S.B. Mende. Global auroral conductance distribution due to electron and proton precipitation from IMAGE-FUV observations. Ann. Geophys., 22, 1595-1611, 2004.

Crowley, G.D.J., K.A. Knipp, J. Drake, E.S. Lei, and H. Lühr. Thermospheric density enhancements in the dayside cusp region during strong $\mathrm{B}_{\mathrm{Y}}$ conditions. Geophys. Res. Lett., 37, L07110, 2010, DOI: 10.1029/2009GLo42143.

Evans, D.S., N.C. Maynard, J. Trøim, T. Jacobsen, and A. Egeland. Auroral vector electric field and particle comparisons, 2. Electrodynamics of an arc. J. Geophys. Res., 82, 2235-2249, 1977. 
Fuller-Rowell, T.J., and D.S. Evans. Height-integrated Pedersen and Hall conductivity patterns inferred from the TIROS-NOAA satellite data. J. Geophys. Res., 92, 7606-7618, 1987.

Huang, C.Y., and W.J. Burke. Transient sheets of field-aligned current observed by DMSP during the main phase of a magnetic superstorm. J. Geophys. Res., 109, A06303, 2004, DOI: $10.1029 / 2003 J A 010067$.

Huang, C.Y., W.J. Burke, B.R. Bowman, F.A. Marcos, J.O. Wise, and C.S. Lin. Thermospheric density modeling during magnetic storms. Proceedings AIAA Guidance, Navigation and Control Conference, Honolulu, Hawaii, 2008.

Huang, C.Y., Y.-J. Su, E.K. Sutton, D.R. Weimer, and R.L. Davidson. Energy coupling during the August 2011 magnetic storm. J. Geophys. Res., 1219-1232, 2014a, DOI: $10.1002 / 2014 J A 019297$.

Huang, Y., C.Y. Huang, Y.-J. Su, Y. Deng, and X. Fang. Ionization due to electron and proton precipitation during the August 2011 storm. J. Geophys. Res. Space Phys., 119, 3106-3116, 2014b, DOI: 10.1002/2013JA019671.

Kelley, M.C., D.J. Knudsen, and J.F. Vickrey. Poynting flux measurements on a satellite: a diagnostic tool for space research. J. Geophys. Res., 96 (A1), 201-207, 1991.

Knipp, D., S. Eriksson, L. Kilcommons, G. Crowley, J. Lei, M. Hairston, and K. Drake. Extreme Poynting flux in the dayside thermosphere: examples and statistics. Geophys. Res. Lett., 38, L16102, 2011, DOI: 10.1029/1022GL048302.

Knipp, D.J., B.A. Amery, M. Engebretson, X. Li, A.H. McAllister, et al. An overview of the early November 1993 geomagnetic storm. J. Geophys. Res., 103 (A11), 26197-26220, 1998, DOI: $10.1029 / 98 J A 00762$.

Knipp, D.J., W.K. Tobiska, and B.A. Emery. Direct and indirect thermospheric heating sources for solar cycles 21-23. Sol. Phys., 224, 495-505, 2004

Li, W., D. Knipp, J. Lei, and J. Raeder. The relation between dayside local Poynting flux enhancement and cusp reconnection. J. Geophys. Res., 116, A08301, 2011, DOI: $10.1029 / 2011 \mathrm{JA} 016566$.

Li, H., C. Wang, W.U. Xu, and J.R. Kan. Characteristics of magnetospheric energetics during geomagnetic storms. J. Geophys. Res., 117, A01225, 2012, DOI: 10.1029/2012JA017584.

Liu, R., H. Lühr, and S.-Y. Ma. Storm-time related mass density anomalies in the polar cap as observed by CHAMP. Ann. Geophys., 28 (1), 165-180, 2010.

Lühr, H., M. Rother, W. Köhler, P. Ritter, and L. Grunwaldt. Thermospheric up-welling in the cusp region: evidence from CHAMP observations. Geophys. Res. Lett., 31, L06805, 2004, DOI: 10.1029/2003GL019314.

Mayr, H.G., and H. Volland. Magnetic storm effects in the neutral composition. Planet. Space Sci., 20, 379, 1972.

McHarg, M., F. Chun, D. Knipp, G. Lu, B. Emery, and A. Ridley. High-latitude Joule heating response to IMF inputs. J. Geophys. Res., 110, A08309, 2005, DOI: 10.1029/2004JA010949.
Newell, P.T., W.J. Burke, E.R. Sanchez, C.-I. Meng, M.E. Greenspan, and C.R. Clauer. The low-latitude boundary layer and the boundary plasma sheet at low altitude: prenoon precipitation regions and convection reversal boundaries. J. Geophys. Res., 96 (A12), 21013-21023, 1991.

Newell, P.T., and C.-I. Meng. Mapping the dayside ionosphere to the magnetosphere according to particle precipitation characteristics. Geophys. Res. Lett., 19 (6), 609-612, 1992.

Picone, J.M., A.E. Hedin, D.P. Drob, and A.C. Aiken. NRLMSISE00 empirical model of the atmosphere: statistical comparisons and scientific issues. J. Geophys. Res., 107 (A12), 1468, 2002, DOI: 10.1029/2002JA009430.

Prolss, G.W. Magnetic storm associated perturbations of the upper atmosphere: recent results obtained by satellite-borne gas analyzers. Rev. Geophys., 18, 183, 1980.

Rich, F.J., and M. Hairston. Large-scale convection patterns observed by DMSP. J. Geophys. Res., 99, 3827-3844, 1994.

Richmond, A.D. On the ionospheric application of Poynting's theorem. J. Geophys. Res., 115, A10311, 2010, DOI: 10.1029/2010JA015768.

Storz, M.F., B.R. Bowman, and J.I. Branson. Dynamic calibration atmosphere (DCA) for the High Accuracy Satellite Drag Model (HASDM), AIAA-2002-4886. AIAA/AAS Astrodynamics Specialist Conference and Exhibit, Monterey, California, 2002.

Sutton, E.K. Normalized force coefficients for satellites with elongated shapes. J. Spacecr. Rockets, 46 (1), 112-116, 2009, DOI: $10.2514 / 1.40940$.

Sutton, E.K., J.M. Forbes, and R.S. Nerem. Global thermospheric neutral density and wind response to the severe 2003 geomagnetic storms from CHAMP accelerometer data. J. Geophys. Res., 110, A09S40, 2005, DOI: 10.1029/2004JA010985.

Vondrak, R.R., and R.M. Robinson. Inference of high-latitude ionization and conductivity from AE-C measurements of auroral electron fluxes. J. Geophys. Res., 90, 7505-7512, 1985.

Weimer, D.R. Improved ionospheric electrodynamic models and application to calculating Joule heating rates. J. Geophys. Res., 110, A05306, 2005, DOI: 10.1029/2005JA010884.

Weiss, L.A., P.H. Reiff, J.J. Moses, R.A. Heelis, and D.B. Moore. Energy dissipation in substorms. Substorms I, ESA SP-335, Paris, Eur. Space Agency, 309-317, 1992.

Wilder, F.D., G. Crowley, S. Eriksson, P.T. Newell, and M.R. Hairston. Ionospheric Joule heating, fast flow channels, and magnetic field line topology for IMF By-dominant conditions: observations and comparisons with predicted reconnection jet speeds. J. Geophys. Res., 117, A11311, 2012, DOI: 10.1029/2012JA017914.

Zhang, Y., L.J. Paxton, D. Morrison, B. Wolven, H. Kil, C.-I. Meng, S.B. Mende, and T.J. Immel. O//N2 changes during 1-4 October 2002 storms: IMAGE SI-13 and TIMED//GUVI observations. J. Geophys. Res., 109, A10308, 2004, DOI: $10.1029 / 2004 J A 010441$.

Cite this article as: Huang CY-Y, Huang Y, Su Y-J, Sutton EK, Hairston MR, et al. Ionosphere-thermosphere (IT) response to solar wind forcing during magnetic storms. J. Space Weather Space Clim., 6, A4, 2016, DOI: 10.1051/swsc/2015041. 